\title{
A Study to Illustrate the Trend of Settlement Pattern and Changes of Housing Condition of Bhetupara, Mohanpur, Rajshahi
}

\author{
Aftabun Nahar*, Imzamam UI Khan Shuvo, Asif Alam, Abdul Wakil \\ Department of Urban \& Regional Planning, Rajshahi University of Engineering and Technology, Rashahi, Bangladesh \\ Email address: \\ himu2010.13@gmail.com (A. Nahar) \\ ${ }^{*}$ Corresponding author
}

To cite this article:

Aftabun Nahar, Imzamam Ul Khan Shuvo, Asif Alam Abdul Wakil. A Study to Illustrate the Trend of Settlement Pattern and Changes of Housing Condition of Bhetupara, Mohanpur, Rajshahi. International Journal of Sustainable Development Research.

Vol. 4, No. 1, 2018, pp. 1-7. doi: 10.11648/j.ijsdr.20180401.11

Received: March 25, 2018; Accepted: April DD, 2018; Published: May 24, 2018

\begin{abstract}
Traditionally, rural settlements were associated with agriculture. In modern times other types of rural communities have been developed. And the Settlement pattern is also changed with time. The study is based on rural housing pattern, because housing is a basic need for mankind. The study area is a village named Bhetupara which is located at Mohanpur upazila in Rajshahi district. The objective of the study is to know about their housing condition and show the trends of changes in settlement pattern. Housing condition represents basically the condition of basic facilities in the village such as sanitation, drinking water facilities and electricity connection. In this paper, he condition is shown trend line analysis and by chart. In the analysis three years data is used to illustrate the trend and compare the present condition in terms of previous condition. The 2001 and 2011 data is collected from Community Series of Rajshahi, and 2017's data is collected from questionnaire survey and field survey. The sample size of household survey was 50 among 171 households and the method used for data sample selection is random sampling method. The study is based on both quantitative and qualitative data. Finally, some recommendation is given to improve the condition of rural settlement.
\end{abstract}

Keywords: Settlement Pattern, Housing Condition, Questionnaire Survey, Trend Analysis

\section{Introduction}

Traditional rural dwellings are usually small, insanitary and suffer from the absence of many of the basic amenities of daily life [7]. The evaluation and indication of these factors behind the condition helps to identify the lacking of these plan in the rural places. In Bangladesh about $80 \%$ of people live in rural settlements, and $86 \%$ of dwelling units are located in rural areas [1]. The present facility in respect to housing and physical infrastructures are very inadequate in rural regions of Bangladesh. Traditionally, rural housing has been taken care by the rural villager's themselves. For showing the present housing settlement pattern, trend of changing settlement pattern and finding some other rural housing aspect a field survey is taken on a village of Mohonpur, Rajshahi. The village is in Maugacchi union and the name of the village is Bhetupara. There are around 171 household in this village. And number of population of this village is nearly 648 [9]. Among them 327 people are male and 321 people are female [9].

The main objectives of this study is to identify the rural settlement pattern and changes in structure type of housing to illustrate the changing pattern of houses to find a trend between present and past condition. To fulfill the purpose of this study, questionnaire survey and field survey is conducted. Many relevant studies have been conducted to identify the housing conditions and settlement pattern by using Geographic information system (GIS) and remote sensing perspective. The study focuses on not only the trend of settlement pattern but also the trend of basic utility facilities that will help to know the influencing factor of these changes. It also shows a relationship between housing structure type and income of people. With the help of local expert and the participation of rural people, the survey run 
very smoothly. From this survey various type of data regarding rural housing was collected. As for example data regarding their settlement pattern, changes of settlement pattern, type of structure, facilities of housing, their opinion etc. This data will help them who will interested for the further rural development plan in Bhetupara village.

\section{Methodology}

The principal objective of this study is to show the changes pattern of housing structure and settlement pattern as stated in introduction. For notifying the actual scenario, questionnaire survey and field survey are conducted. The present study includes changes in basic facilities of housing such as sanitation, drinking water facilities and electricity connection. For this study, literatures are reviewed for two times. First one is for choosing the topic and second one is to know about types of human settlement pattern. The study takes overview some reports to analyze the objectives. These help to understand how can get the result. In this study both quantitative and qualitative approach has been used for the survey. Random and cluster sampling approach have been adopted to select respondents for quantitative survey. Bhetupara has been divided into several groups of houses and one respondent has been selected randomly from the groups. The data was collected from primary and secondary sources. Respondents were requested to give us answer of the questionnaires for existing condition and the previous data which needed to fulfill the objectives is collected from BBS (Bangladesh Bureau of Statistics). Then the data are being analyzed. And finally some recommendation are given.

\section{Literature Review}

The history of civilization shows that over centuries man developed through trial and error a fine tradition of region and culture-specific architecture which still persists in the rural habitats in different parts of the world [12].

Rural Housing:

Housing is a basic human need and as such provision of adequate housing for all citizens is almost universally recognized by government around the globe as one of their fundamental responsibilities. And yet housing remains a serious problem in most of the developing countries, and even in many developed countries. In the case of developing countries particularly, the gap between the demand and supply of adequate housing is continually increasing. This gap has been of alarming proportion in Bangladesh. The reasons for such gaps are several, including the existing social structure rapid population growth, persisting poverty, and recurring natural hazards, but, also an unclear perception about the role of housing [3].

Human Settlement Pattern:

This book is about Human Settlement. They have discussed about population composition, total population, rural-urban population; population growth, etc. In this lesson, their focus is on human settlements. Therefore, discussion will revolve around the concept of settlements meaning and nature, evolution and classification of rural and urban settlements [2].

Rural Housing Material:

In Their book M. Hasan, M. S. Ullah and C. D. Gomes analyze the rural housing in Bangladesh is described. They focused on housing typology, construction technology. Though there is much similarity than difference in geographic condition, there are some variations in the housing characteristics. Majority of the houses is temporary in nature. The houses that are commonly found in Bangladesh are described here. And also the characteristics of housing materials in rural area of Bangladesh is described. Mainly there are some types of material used on rural area [1]. They are:

a) Bamboo Walled Houses

b) Mud Walled Houses

c) Timber House

d) Timber and Brick Built Houses

e) Corrugated Iron (CI)/ Tin Sheet Houses

f) Thatch/ Straw Walled House

A study is conducted by Ferdous et.al in Dhaminkaur and KhordKaur villages of Baghmara Upazila, Rajshahi with the help of Participatory Rural Appraisal (PRA) tools i.e. key informants' interview, transect walk and direct observation throughout the study area. Geographic Information System (GIS) has been applied to see the decadal change in settlement pattern in the year between 2003-2016. According to the study, a significant change has noticed in the housing settlement pattern in the last 13 years. Influential factors behind the housing condition and reason for changing condition have been identified. Main reason for changing conditions are: increase in income and migration rate, variation in income source, and Reduction of joint family. It revealed that the housing condition in the study area is Moderate [11].

\section{Study Area}

A study area is geography for which data is analyzed in a reporter map. Business decision offers two ways to define study areas: Site based study area \& Geographical unit based study area. This study is not related to business decision. The purpose is to observe housing utility condition \& find out a trend of hosing pattern in rural context. So, a village is chosen for this study.

The study area is located at Mohanpur upazila in Rajshahi (figure 1). The name of the village is "Bhetu para" in Bakshimail union. It is 35 kilometers away from main town of Rajshahi and 8 kilometers from Mohanpur. It is mainly an agricultural based village. There are 171 households in Bhetupara according to BBS. This study considers only Bhetupara village as the study area. All the respondents are from Bhetupara \& village. The main crop of this area is betel leaf. 


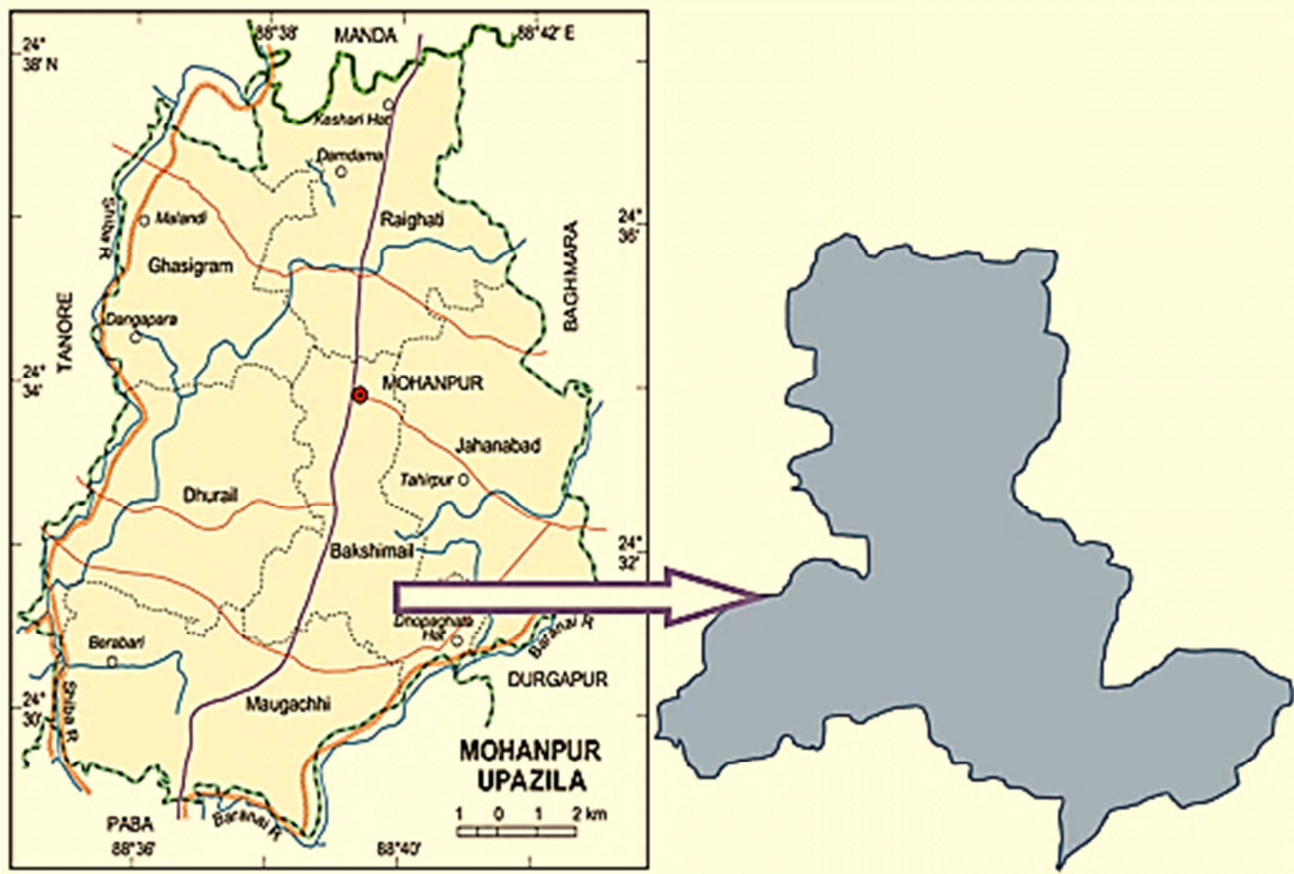

Source: LGED Map, 2017 [10].

Figure 1. Study area map.

\section{Data Analysis and Results}

The Trend Analysis module allows to plot aggregated response data over time. This is especially valuable, if anyone are conducting a long running survey and would like to measure differences in perception and responses over time [6]. In this study there is used 3 years data. 2001 and 2011's data is collected from Bangladesh Bureau of Statistics (BBS) and 2017's data is collected from field survey 2017. The analytical result is described below.

\subsection{Settlement Pattern}

A settlement pattern refers to the shape of the settlement. The shapes of early settlements were influenced by the surrounding landscape. They were also shaped by other factors such as who owned the land and whether the land was good for building on or not [5]. Mainly there are three types of settlement pattern and they are shown in table 1.

Table 1. Types of settlement pattern.

\begin{tabular}{lll}
\hline Compact & Semi-compact & Helmeted \\
\hline a) Linear pattern & a) Checker board & \\
b) Rectangular pattern & b) Elongated & \\
c) Square pattern & c) Fan shaped & \\
d) Circular pattern & \\
e) Radial pattern & \\
\hline
\end{tabular}

Source: Online, 2017.

The trend of the settlement pattern of the study area are described below:

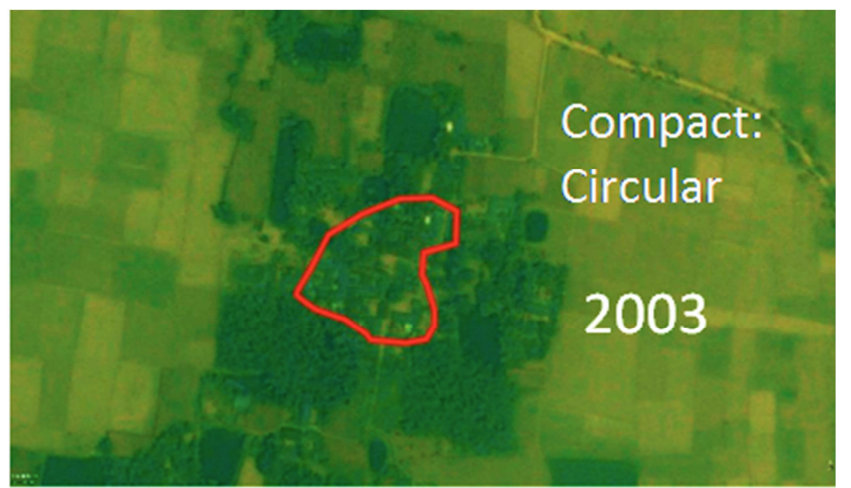

Source: Google Map, 2003

Figure 2. Settlement pattern change in 2003

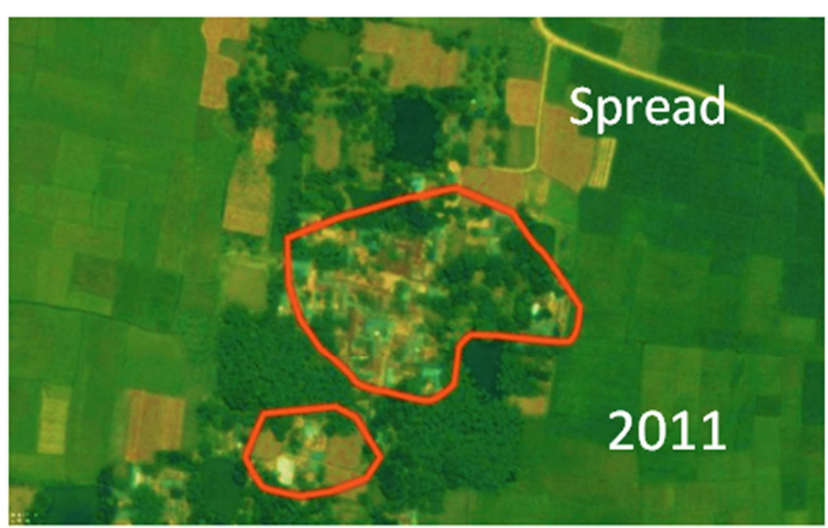

Source: Google Map, 2011.

Figure 3. Settlement pattern change in 2011 
Here the figure $2 \& 3$ shows the changing pattern of settlement in terms of different time. At fast in 2003 the settlement type was compact and circular. Because the population was less. But after time passes population increases as a result number of houses also increases. That's why in 2011 the in the map it can be seen that the settlement started spreading.

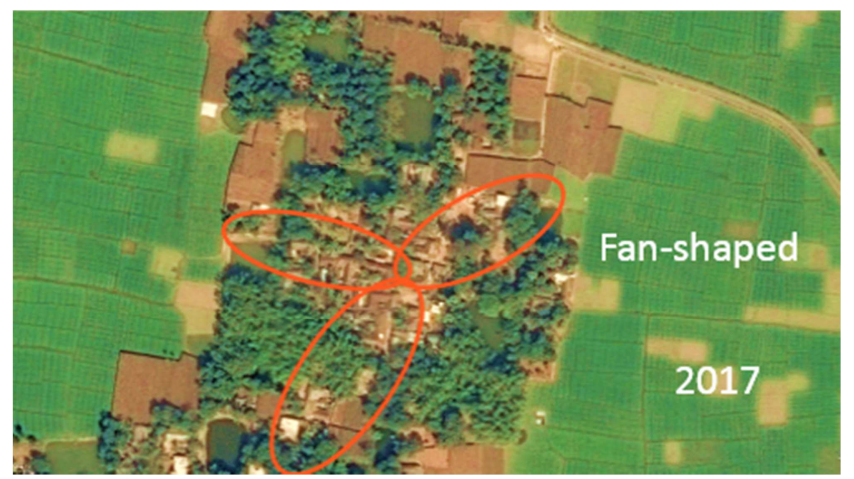

Source: Google Map, 2017.

Figure 4. Settlement pattern change in 2017.

And now in 2017 it is noticed that the settlement pattern turned into fan-shaped which is a part of semi-compact settlement pattern (figure 4). That's why it can be said that the settlement pattern in becoming semi-compact. The reasons of changes in pattern are.

a) Peoples like to build their houses near to community facilities,

b) Building houses alongside the road,

c) Increase in number of nuclear family,

d) Betterment of economic condition,

e) Absence of proper planning etc.

\subsection{Housing Structure Type}

According to house building material house can be categorized as: a) Katcha; b) Semi-pucca; c) Pucca; d) Jhupri.

In this study for housing structure type portion 2011 and 2017 data is used. The majority of the respondent engaged into agricultural activity and their income level is also very low. That's the reason for increasing the number of kutcha houses in 2011. And now almost every household has working members and their income level is also increasing. That's why the number of semi-pucca houses has the larger number. Below the chart showing the trend of housing structure type (figure: 5).

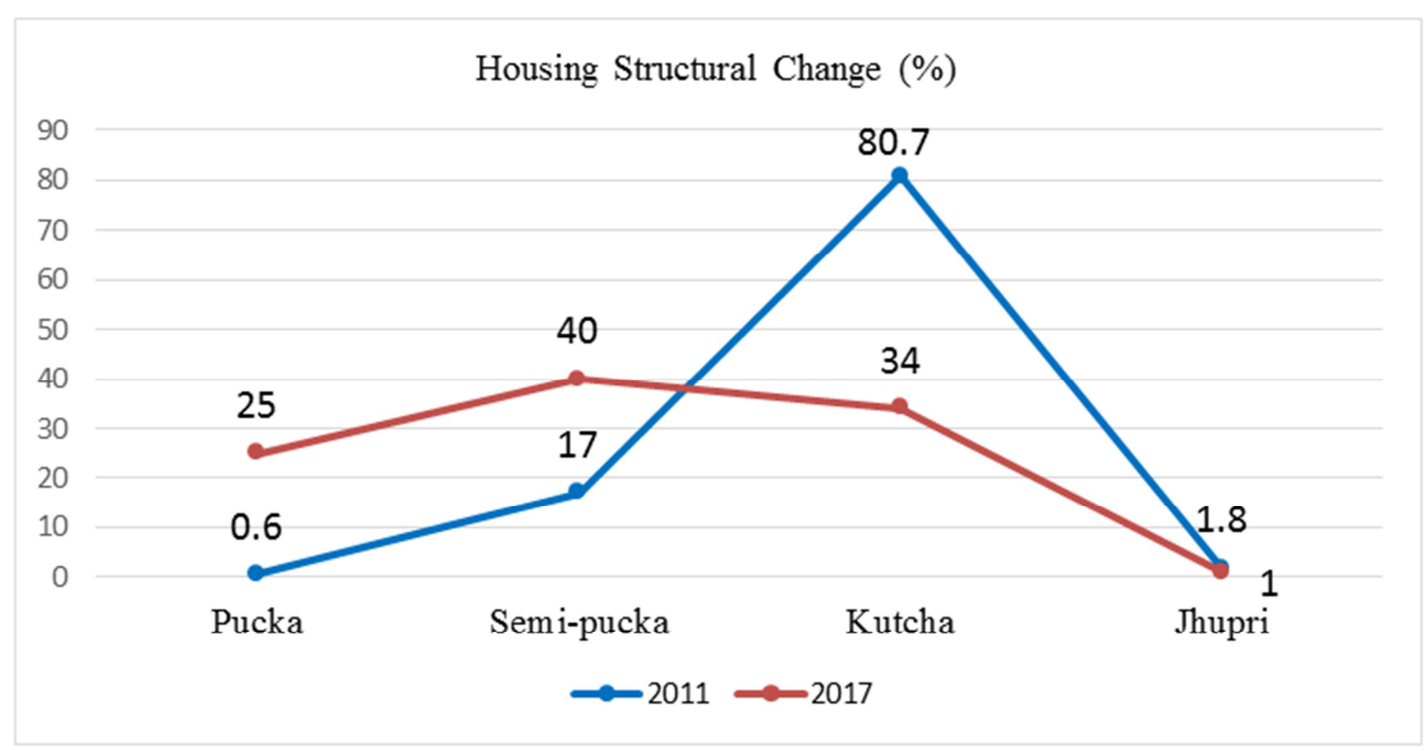

Source: Bangladesh Bureau of Statistics (BBS), 2011 \& field survey, 2017

Figure 5. Trend line of changes in housing structure.

Here in this figure 4, it is seen that the number of kutcha structure is greater in 2011. And the percentage was $80.7 \%$. And semi-pucca (17\%) was in the second position. Pucca house was rarely seen. And there are some jhupri (1.8\%) also. In 2017 the percentage of kutcha house decrease to $33.33 \%$ with the increase of the percentage of semi-pucca $(40 \%)$ and pucca house $(26.67 \%)$. Because the income level of people are consistently increasing. It can be easily seen that in 2011 the kutcha house is greater but now in 2017 it decreases. The pucca and semi-pucca house is greater in 2017.

\subsection{Sanitation}

In Bhetupara the condition of sanitation facility is not bad at all. Because they are concern about the consequence of bad sanitation. The trend of the study is describe below (shown in figure 6):

It can be seen that the sanitation condition of Bhetu para village in 2001 was not bad because the sanitary (Non-water sealed) water facility is greater (80.5) there [8]. Non sanitary is only $30.1 \%$. According to the 2011 data it can be seen that 
the sanitary (Non-water sealed) toilet facilities percentage decreases to $46.2 \%$ from $80.5 \%$. And non-sanitary toilet facility increases from 30.1 to $45.6 \%$. The reason behind the percentage decrease in sanitary (Non water-sealed) water facility is the number of new built house increase but with the increases number of house sanitary (Non water-sealed) toilet facility does not increase but the non-sanitary toilet facility increase. This is the reason for increasing the number of non-sanitary toilet facility. And now in 2017 it can be seen that the percentage of sanitary (Non water-sealed) increases again. And there are also some sanitary (water-sealed) toilet facility are found.

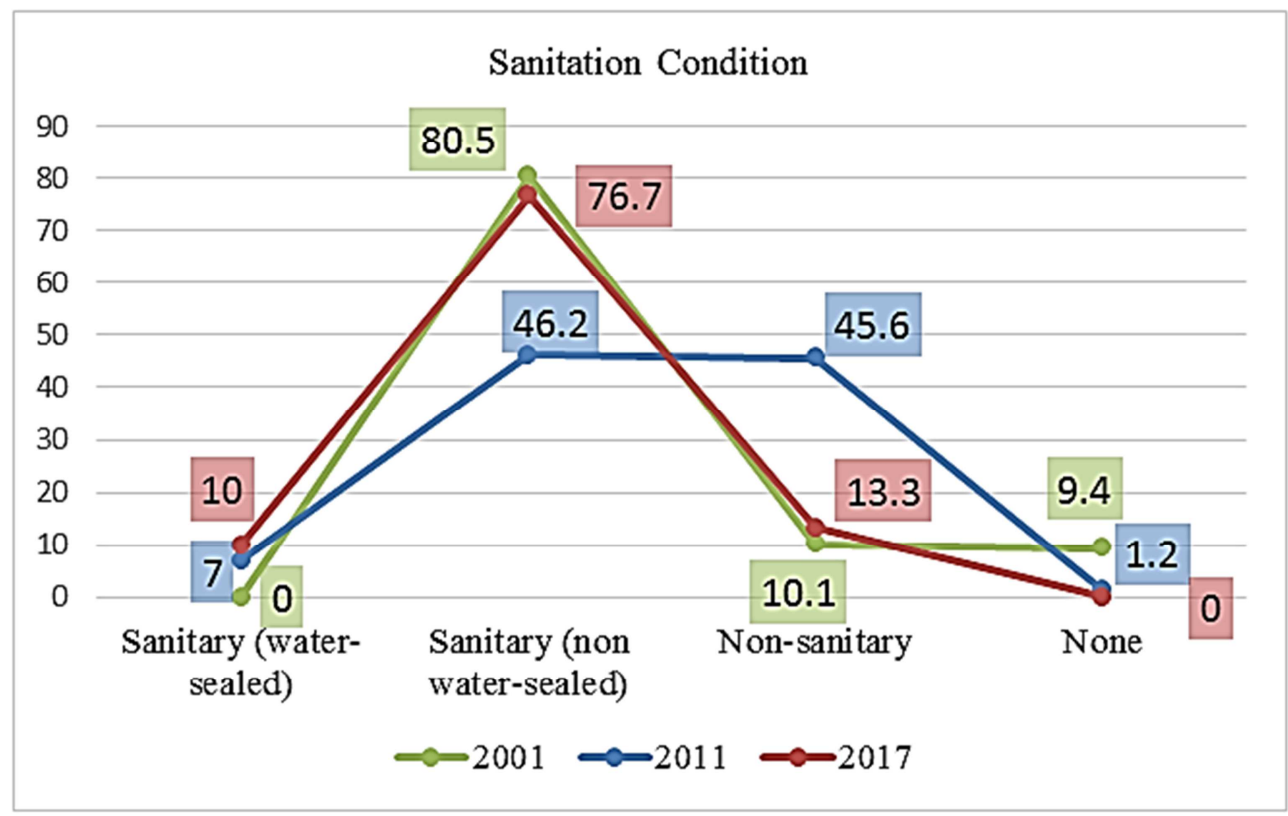

Source: Bangladesh Bureau of Statistics (BBS), $2001 \& 2011$ \& field survey, 2017.

Figure 6. Sanitation condition changing pattern (Trend Line).

This trend line shows the changing pattern of sanitation facility according to some time zone. After seeing this trend line anyone can clear about the condition of the sanitation facility of Bhetu para.

\subsection{Drinking Water Source}

Drinking water is a major utility facility of an area. In
Bhetu para village there is no such problem of getting pure drinking water according to the opinion of the respondents. Here in this chart the trend line of drinking water source is shown figure 7 . Here it can be seen that the percentage of tube-well decreases after time passes with the increases of the new drinking water source.

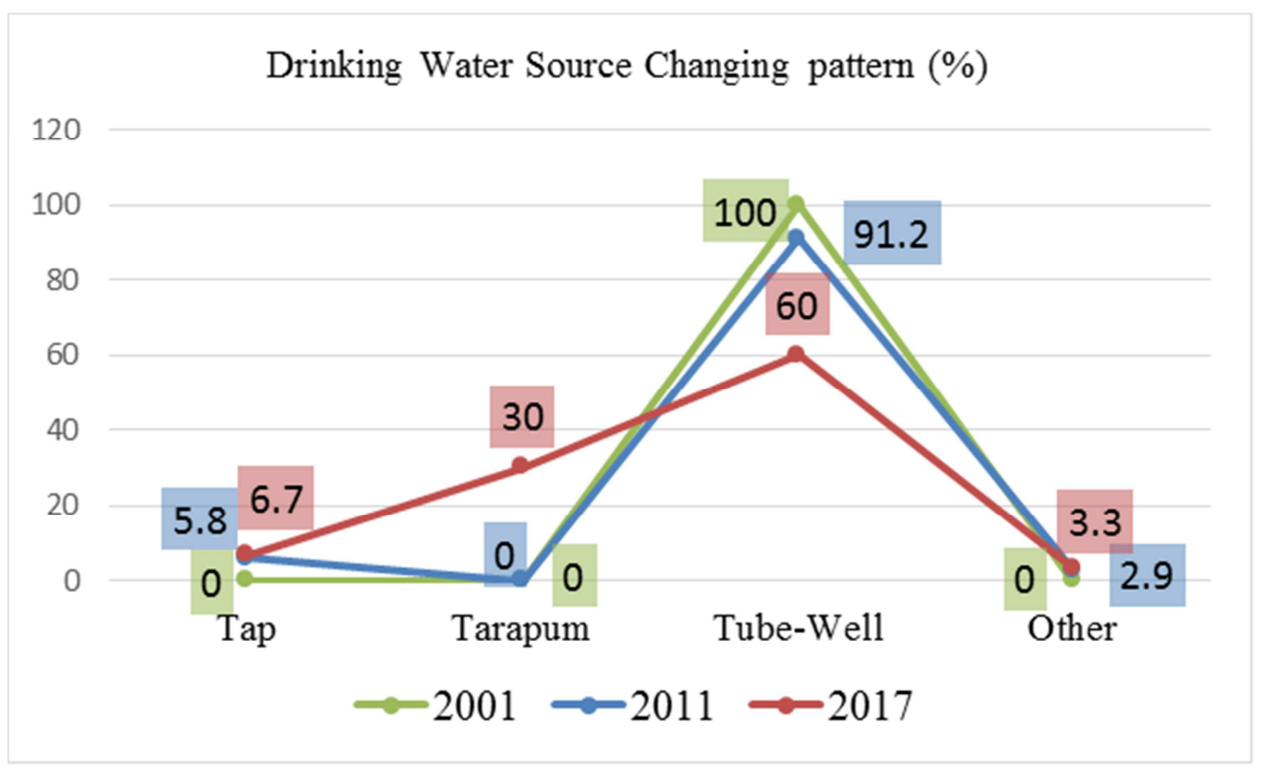

Source: Bangladesh Bureau of Statistics (BBS), 2001 \& 2011 \& field survey, 2017.

Figure 7. Drinking water source changing pattern (\%). 
According to this chart of 2001 it can be easily seen that the only and one drinking source is tube-well. And every household got this facility which is near from house. They do not have any problem regarding this topic. In 2011, it can be easily seen that other than tube-well there is tap drinking water source is available and some other facilities also available. Here other means irrigation water. And now in 2017 it is seen that there is a new type of water source is available there. Which is tarapam (30\%). Because of this new water source the percentage of tube-well decreases.

\subsection{Electricity Connection}

Life comes to near standstill after sunset for the great majority of Bangladeshis living in the countryside. Only about $40 \%$ of rural households have access of grid electricity, and even these consumers suffer frequent and prolonged power cuts due to lack of supply [4].

Electricity connection is the major utility facility in any area. Without it everything will stop working. Because everything is dependent on electricity facilities.

This chart shows the electricity condition of Bhetupara in three different times (figure 8). At first in 2001 from the chart it can be seen that there is no electricity facilities available in Bhetu para village according to Bangladesh Bureau of Statistics 2001. But after time passes the electricity connection became available in the village. And in 2011 the percentage was $80.7 \%$. And now almost every house got electricity facility.

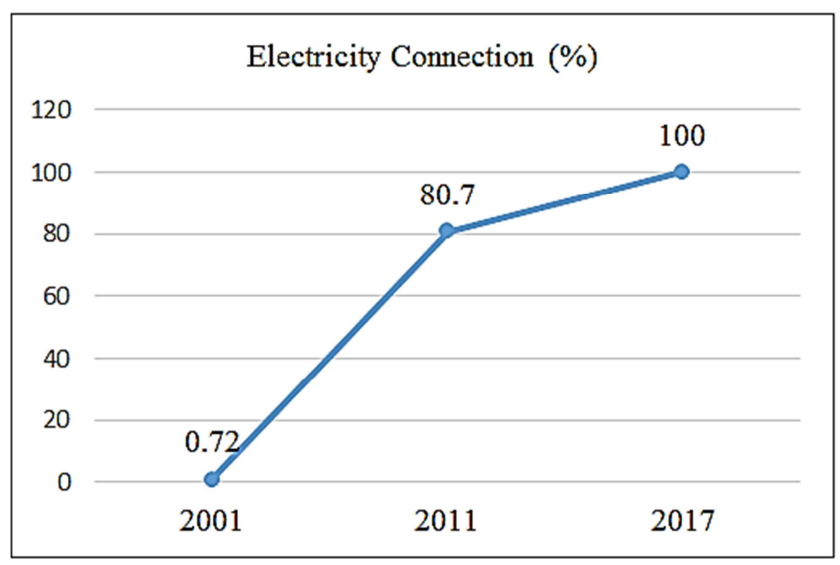

Figure 8. Electricity Connection (\%).

Source: Bangladesh Bureau of Statistics (BBS), 2001 \& 2011 \& field survey, 2017

\subsection{Relationship Between Housing Structure Types and Income of the Respondent}

This study make an analysis between income of the respondents and housing structure types of the respondents and tries to find a relationship among the two variables shown in table 2.

Table 2. Relationship between housing structure types \& income of the respondents.

\begin{tabular}{llll}
\hline Correlations & & & Income of the respondent \\
\hline & & 1 & Housing Structure type \\
\hline & Pearson Correlation & $.779^{* *}$ & .000 \\
Income of the respondent & Sig. (2-tailed) & 25 & 25 \\
& $\mathrm{~N}$ & $.779^{* *}$ & .000 \\
Housing Structure type & Pearson Correlation & 25 & 25 \\
& Sig. (2-tailed) & $\mathrm{N}$ & \\
\hline
\end{tabular}

Source: Field survey, 2017

After doing the correlation it is seen that the income of the respondent and housing structure type is positively and highly correlate with each other.

\section{Recommendation}

a) Improving Housing Facilities:

The condition of housing is not good in Bhetupara. There should have to improve some facilities like good access road, supply drinking water, and water sealed sanitation.

b) Employment generation:

It is noticed that maximum respondent of Bhetupara are farmer. Nowadays the improvement of new technology, there are many type of crop invented which have greater production than past but because of using many pesticides and fertilizer the fertility of land is decreasing day by day. As a result many farmer are not getting the profit. Many people migrate to the city form the village for work facilities. So, there need many source of non-agriculture based employment opportunity. In respect to the women all are housewife but they can do many things like handicraft activity. They need proper training and some economical support.

c) Infrastructural development:

For communication and transportation of goods and people, a good transportation system is needed. In Bhetu para the access road are kutcha, as a result there occurs disturbance in communication. So, there needed development of road and other infrastructure like community clinic, educational institution and information center.

d) Educational facilities:

In Bhetupara there is no primary school available. So, it is needed to build up a primary school there. And parents are need to be aware of sending their children to the school.

e) Research on betel leaf:

In Bhetupara maximum people are cultivate betel leaf and 
it is the only means of livelihood for some people. They claimed that because of proper knowledge, they cannot produce the maximum amount and sometimes they faced many problem in term of production, so, it is needed to research on betel leaf and provide them every information.

\section{Conclusion}

Housing not only means a mere form of shelter but also it includes all those qualities of comfort, convenience and environmental amenities essential for social and emotional well-being of families. So, housing must be taken as first concern. In Bhetupara, housing structure and facility are not so good. Because maximum peoples do not have money to develop there structure. Most of the structure are semi-pucca. Which is built by brick wall and tin shed. In terms of utility facilities the electricity connection, drinking water supply are good but the condition of access road is very bad because most of the portion of road is kutcha (mud road). In rainy season they face many difficulties in movement of people and goods. But, Bhetupara has potentialities to improve and there are many scope for development such as land, natural resources, man power, near from Rajshahi etc. So, generation \& variation of employment may help to develop their condition.

\section{References}

[1] Hasan, M., Ullah, M. S., \& Gomes, C. D. (2000). Rural Housing In Bangladesh: An Inquiry Into Housing Typology, Construction Technology And Indigenous Practices. The Proceedings of H \& H Conference (2000), Dhaka.

[2] Human Settlement (2013). Retrieved 06, May, (2017), from https://www.google.com/url?sa=t\&source=web\&rct $=\mathrm{j} \& u r l=h t t$ p $\% 3 \mathrm{~A} \% 2 \mathrm{~F} \% 2 \mathrm{Fwww}$.nos.or \%2Fmedia\%2Fdocuments\%2F31 6courseE\%2Fch28.pdf\&ved=0ahUKEwi39piJmOvTAhUI
48KHYH DoYQFggdMAE\&usg=AFQjCNH2F0kP8qVgQO Srbwl1Zaovov5qcg

[3] Islam, N. (1990). HOUSING IN BANGLADESH: AN OVERVIEW. Journal of Bangladesh Institute of Planners, 1, $37-45$.

[4] Roy, K. K. (2014). Lighting Up Rural Communities in Bangladesh. Retrieved May, 8, 2017, from http://www.worldbank.org/en/news/feature/2014/01/15/lightin g-up-rural communities-in-Bangladesh

[5] SETTLEMENT PATTERNS. (2017). Retrieved 06, May, 2017, from http://www.3dgeography.co.uk/settlement-patterns

[6] Trend Analysis - Analyzing Aggregate Response Data Over Time. (2017). Retrieved 06, May, 2017, from https://www.questionpro.com/article/trend-analysis.html

[7] R. Hafiz, "Financing Housing and Increasing Affordability of the Rural People in Bangladesh, Bangladesh," BUET, 2000.

[8] BBS (2001). Population And Housing Census, Rajshahi, Bangladesh Bureau Of Statistics (BBS), Statistical and Informatics Division (SID), Ministry of Planning, Government of The People's Republic of Bangladesh.

[9] BBS (2011). Population And Housing Census, Rajshahi, Bangladesh Bureau Of Statistics (BBS), Statistical and Informatics Division (SID), Ministry of Planning Government of The People's Republic of Bangladesh, December 2013.

[10] LGED. Local Government Engineering Department. [Cited 2017 April 16]; Available from: http://www.lged.gov.bd/

[11] Ferdous, L., Kafy, A., Gafur, A. M. R. \& Wakil, M. A. (2017). An Analysis on Influencing Factors of Rural Housing and Settlement Pattern in Rajshahi, Bangladesh. Landscape Architecture and Regional Planning. Vol. 2(4), pp. 99-109. doi: 10.11648/j.larp.20170204.12.

[12] Traditional House Form in Rural Bangladesh: A case study for Regionalism in Architecture (2017). Retrieved 07, May, (2017) from http://arcnet.org/system/publications/contents/3676/original/D PC0287.pdf?1384775936 